hospital with his symptoms little, if at all, relieved. In a month or two he complained of very severe pain in the right iliac fossa, and an abscess formed and discharged itself through the scar in the loin. Mr. Sutton, who saw the patient at his own home, reported: "The temperature and general nature of the illness, taken together with what I knew of the patient in the hospital and saw at the operation, led me to the opinion that his condition was due to tuberculous mischief about the cæcum, probably of the vermiform appendix." The abscess did not close, and, later on, fæcal matter escaped through the sinus. Mr. Sutton therefore examined the sinus under chloroform, and found a large opening in the posterior aspect of the ascending colon, near the cæcum. The patient died some months later, but a post-mortem examination was not permitted.

The previous attack of peritonitis, the ill-defined mass in the right ilio-costal region, which disappeared in the operation position (probably infiltration of the cæcum and appendix), the comparatively slight amount of disease in the kidney, and the subsequent fæcal fistula, render it impossible, I think, not to concur with Mr. Sutton in thinking that disease about the cæcum was the cause of all the symptoms in this case. It is well known that intestinal irritation simulates nephralgia by causing lumbar and iliac pain, sometimes of a paroxysmal character, by vomiting, tenderness on pressure, and urine loaded with urates.

The case I have referred to above, in which a gastric ulcer of old standing was the only pathological condition found post mortem, may have had in this ulcer the foundation and cause of the symptoms, even though these symptoms were referred to the left and not the right kidney. The fact that the patient had passed a small calculus does not allow of the case being placed under the class in which the symptoms were due to "the effect of the former passage of a stone," because, in spite of a thorough examination after death, no pathological change whatever was found in any part of the urinary system, and no disease in any other organ except the ulcer of the stomach. Dr. Ralfe has reported a case ${ }^{2}$ in which many of the symptoms of right renal calculus were excited by a duodenal ulcer, and another in which they were due to intestinal irritation.

In suspected renal calculus one of the errors of diagnosis to be borne in mind is the possibility of the symptoms being caused by ulcer of the cæcum, duodenum, or stomach, or by some other form of intestinal affection. In this connection let me mention that $I$ have known other forms of renal disease simulated by diseases of the large bowel; thus cancer of the cæcum has been, by a well-known hospital physician, mistaken for movable kidney, and was later on the cause of an enormous abscess behind the right kidney, which had to be opened through the loin; and another case I operated upon for what was suspected to be a renal abscess, a patient of Mr. Court, of Staveley, proved to be an abscess in the cellular tissue below and behind the kidney, the origin of which was malignant disease of the sigmoid flexure.

Renvers has published a case of intermittent hydronephrosis with gastric crises. ${ }^{3}$

2. Abscess of the Kidney. - In 5 cases abscess in the kidney was found instead of a calculus. All the patients were males; 3 were tuberculous, in one the abscess was secondary to long standing and neglected stricture of the urethra, and the fifth occurred in a gouty man in whom no definite cause for suppuration was found. In the kidney of this man, aged 43, with stricture of the urethra, there was a small suppurating cyst at the posterior part, and the lower half of the organ was almost entirely converted into a large abscess. These were opened, and the cut edges of the kidney stitched to the margins of the skin. A urinary sinus resulted through which all the urine secreted, amounting to about 40 ounces in 24 hours, was discharged into a urinal worn at the loin. It was proved to perfect certainty by the result of the operation that the right kidney was the only renal excreting tissue he had, and thus the operation not only relieved him of his suffering, but, by stopping further destructive changes in his kidney, saved his life. He lived for two years and nine months after the operation. In 2 of the 3 cases of tuberculous abscess nephrotomy failed to relieve the symptoms, and consequently nephrectomy was performed, in one two months

\footnotetext{
2 BRITISH MEDICAC JOURNAL, 1888, vol. i, p. 183.

Derliner klinische Wochenschritt, December 3ist, 1888.
}

and in the other a few days after the nephrotomy. In both cases there were multiple abscesses and pyelitis. In neither did I feel justified at the time to nephrectomise. In one case some hope was entertained for a few weeks that improvement would be permanent : this was, however, disappointed, and the kidney was removed piecemeal from within its capsule two calendar months after nephrotomy. Death followed on the third day from exhaustion, and at the post-mortem examination, though the right kidney was unaffected, the prostate, bladder, and left vesicula seminalis as well as the left testis were all the seat of advanced tuberculous disease.

In the other case very acute febrile symptoms with rapid increase in the size of the explored kidney occurred immediately, so that, after consultation with Dr. Powell as to the state of the man's lungs, I removed the kidney on the third day after nephrotomy. The excised kidney was greatly enlarged from acute inflammation and general tuberculous infiltration. The patient made a slow but steady recovery, and is now, fifteen months after operation, at his work and well. A small superficial sinus in the loin was closing when last seen in January.

The third tuberculous case is the most interesting and encouraging of all. There were marked symptoms of renal calculus, and four small calculi passed by him at different times are in the possession of his doctor, Mr. Pound, of Odiham. For ten weeks he had been completely disabled. On bringing the kidney (right) on to the surface of the loin, it was found enlarged and botryoidal in outline from the bulging of six distinct and separate cyst-like swellings, each of which contained thick yellow cheesy material. Four of these were situated along the convex border of the kidney, one on the anterior, and the sixth on the posterior surface. They were all opened freely and the contents evacuated; the inner walls of the cavities were then well rubbed with pellets of cotton-wool, and iodoform was liberally sprinkled over the interior. The kidney was then put back into position and the wound closed by buried and superficial sutures. All symptoms subsided at once-except that he still passed a trace of pus in his urine-and the wound healed by the first intention.

In the fifth case an abscess in the left kidney, containing only about $3 \mathrm{ij}$ of pus, was evacuated. The man, aged 34 , was of robust appearance, and for three years had suffered from attacks of gout. His symptoms had existed for two years, and consisted of severe pain in the left loin; suddenly coming on and extending along the crest of the ilium to the left groin and testis; vomiting and rigors, frequent micturition, and blood, pus, and numerous phosphatic crystals in the urine. The operation was followed by complete recovery, and the patient called at the hospital the following year to report himself as continuing well.

In all these five cases of abscess there was localised pain in the renal region, in three tenderness on pressure, in all blood and pus in the urine, in four vomiting or retching, in three frequency of micturition, in two rigidity of the abdominal muscles of the affected side, with some fulness and dulness in the loin. Of the five cases, one died after secondary nephrectomy, performed only as a means of relief-too many other organs being affected with tubercle to permit of a hope for more than relief. The other four cases received great benefit from-and it is, perhaps, hardly too much to say owed their lives to-the operations.

\section{TRAUMATIC HYDRONEPHROSIS.}

By W. J. COLLINS, M.S.Lond., F.R.C.S., Surgeon to the London Temperance Hospital ; Assistant Surgeon to the Royal South London Ophthalmic Hospital.

Traumatism is nowadays usually enumerated by systematic writers on renal diseases as one of the causes of hydronephrosis. The earlier cases recorded as belonging to this category are not always clearly interpreted, and the treatment recommended has varied not a little. Traumatic hydronephrosis has been regarded as of great rarity; Rayer does not allude to it, ${ }^{1}$ but probably most surgeons of experience could recall cases within their knowledge. Of 142 cases of hydrone-

\footnotetext{
1 Rayer, Maladies des Reins, 1841, tom. iii.
} 
phrosis examined at Middlesex Hospital, H. Morris ${ }^{2}$ does not find one attributed to traumatism, although he cites reported cases "in which hydronephrosis has followed an injury to the renal region." Of the three cases which I now record, the two first were undoubtedly traumatic hydronephrosis; the third probably was related to the other two, but its nature must remain doubtful.

CASE I. Run Over: Fractured Pelvis, Collapsed: Later, Hydronephrosis, Right Loin : Repeated Aspirations : Cure.-G. W., aged 5, admitted into London Temperance Hospital on November 5th, 1889, in a collapsed state, having been run over by a cart, the wheel passing over the abdomen and
pelvis. There was fracture of the left lower ribs and of the right os inpelvis. There was fracture of the left lower ribs and of the right os innominatum near the eminentia ilio-pectinea. The collapse suggested visceral lesion : the catheter drew off only a drachm or two of sanious
urine. However, injection of the bladder with two ounces of boracic urine. However, injection of the bladder with two ounces of boracic acid solution, and the subsequent recovery of the same quantity by bimanual expression proved that this viscus was unruptured. For some days the urine was blood-stained, but he made a good recovery and was discharged on November 30th, passing about 23 ounces of urine per diem. $A$ week later he was readmitted on account of a painless swelling disto Poupart's ligament, and inwards to the navel. The colon was easily felt in front of the tumour; there was fluctuation. On deep palpation in the right inguinal region, a hard, sessile, mass was felt at or near the pelvic brim, which was presumed to be callus at the site of the pelvic fracture. There was no pain or fever, the general condition was good. The urine was normal, but was reduced to less than half a pint per diem, sometimes only 6 ounces.

December 10 th, 1889. I aspirated the tumour from the loin, withdrawing 18 ounces of pale amber-coloured fluid, of specific gravity 1003 , faintly

alkaline, containing a trace of albumen and 1 per cent. of urea.

The swelling rapidly returned, and on December 16 th, 20 th, and 30th, I again aspirated, withdrawing 25,29 , and 30 ounces respectively. Since again aspirated, withar increasing intervals down to May 21st, 1891 , the patient coming up for this purpose as reaccumulation occurred. There patient coming up for this purpose as reaccumulation occurred. There preciable return of the swelling, and the boy is in excellent health. The dates and amounts of the various tappings are as follows :

\begin{tabular}{|c|c|c|c|c|c|c|c|c|c|c|c|}
\hline 1889 & cem & $r 10$ & ... & 18 & ounces. & 1890, & April & 14 & ... & 16 & ounce \\
\hline$"$ & ", & 16 & $\ldots$ & 25 & , & , & May & 22 & $\ldots$ & 14 & " \\
\hline$"$ & " & 20 & ... & 29 & " & ", & July & 14 & $\ldots$ & 9 & " \\
\hline 1890 & Jan̈uary & $\begin{array}{l}30 \\
13\end{array}$ & $\cdots$ & 30 & " & " & August & 25 & $\cdots$ & 9 & 7 \\
\hline & & 27 & 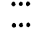 & 26 & " & 189̈1, & January & 8 & $\ldots$ & 6 & " \\
\hline ", & $\begin{array}{c}\text { February } \\
\text { March }\end{array}$ & $\begin{array}{r}10 \\
3\end{array}$ & $\ldots$ & $\begin{array}{l}22 \\
20\end{array}$ & & , & $\underset{\text { May }}{\text { March }}$ & $\begin{array}{l}16 \\
21\end{array}$ & $\ldots$ & $\begin{array}{l}6 \\
\text { B }\end{array}$ & ", \\
\hline
\end{tabular}

No reaction or inconvenience at any time followed aspiration; the contents of the cyst were never offensive or turbid; the aspirating needle was sterilised by boiling water before use. The daily amount of urine wassed (that is secreted by the opposite kidney) rose from an average of passed (that is secreted by the opposite kidney) rose rom an average of in February $1890 ;$ which is probably nearly the normal for his age.

in February 1890 ; which is probably nearly the normal for his age.
CASE II. Injury to Left Loin by Fall: Hydronephrosis : Relieved by AspiraCASE II. Injury to Left Loin by Fall : Hydronephrosis : Relieved by Aspira-
tion: Recurrence Eleven Years later with Serious Symptoms : Drainage of Sac: tion : Recurrence Eleven Years later with Serious Symptoms : Drainage of Sac: fecovery. - F. B., aged 36, a painter, formerly a sailor, in Novenber, 1880, much collapsed, and was admitted to Haslar Hospital. He says a swellmuch collapsed, and was admitted to Haslar Hospital. He says a swellrated, some clear fluid having been withdrawn. He suffered from much rated, some clear fluid having been withdrawn. He suffered from much abdominal pain and vomiting, and from obstinate constipation. He was aspirated seven times in all during the five months that he continued in Haslar Hospital. From that time he continued well until May, 1891, when he again began to suffer from great pain in the abdomen and lumbar region with obstinate constipation. For this he was admitted into the London Temperance Hospital on May 7th, 1891, under my care. He was emaciated and looked ill, the abdomen was distended and could be palpated with difficulty ; bimanually there was increased resistance in the left ilio-costal interval, and fluctuation could be elicited with some diffi culty; there was much tenderness on pressure. The superficial veins were distended ; there was no external hernia ; sickness and constipation were troublesome. Urine, specific gravity, 1020; some pus, albumen, and renal epithelium.

May 25th. Aspiration left loin; 34 ounces of opaque fluid, containing pus, withdrawn ; much relief.

May 31st. During the last few days the pain and sickness have returned; he does not take his food; tongue furred and inclined to dry. Under chloroform an incision 4 inches long was made between the last rib and the iliac crest, and the hydronephrosis exposed; this was found to extend upwards to the ninth rib, downwards to the iliac crest, inwards to the upwards to the ninth rib, downwards to the iliac crest, inwards to the stitched to the parietal wound, and the interior swabbed out with a 20grain to the ounce solution of chloride of zinc. Three or four minute
grain to grain to the ounce solution of chloride of zinc.

For a week after the operation the discharge was very copious, necesFor a week after the operation the discharge was very copious, neces-
sitating frequent dressings, but after this the wound gradualiy consitating frequent dressings, but after this the wound gradually coning only a sinus about 3 inches long, leading into a cavity of a capacity of ing only a sinus about 3 inches long, leading into a cavity of a capacity of the following results, for which I am indebted to Dr. Wilde

Urine. -20 ounces in twenty-four hours; specific gravity, 1020; acid, no albumen; urea $=0.8$ gramme per 100 c.c., or 4.53 grammes per diem.

Fluid. - 16 ounces in twenty-four hours; specific gravity, 1003; neutral, albumen half column on standing; urea $=0.8$ gramme per 100 c.c., or 3.62 grammes per diem.

He was discharged September 7 th, wearing an india-rubber tracheotomy tube, stiffened with metal inside, and a tube leading from this into a flat feeding bottle fitted to the thigh. He had gained 15 lbs. in weight since the operation.

CASE III. Fall from Horse : Injury to Left Loin : Hæmaturia : A Fortnigh

H. Morris, Surgical Diseases of the Kidneys, chapter xxi, pp. 294-5.
Later Evidence of Blood-sugillation in Left Lumbar Region and Renal Tumour: Recovery.-C. A., aged 30, a mounted policeman, was riding his horse on Fisuary 11th, 1891, when it fell and threw him. He fell "all of a heap," his left side coming against the ground. He was much shaken, a little collapsed, and he vomited. He reached the barracks with assistance and was then brought on to the London Temperance Hospital, where he was admitted under my care. His temperature was $96^{\circ} \mathrm{F}$
frequently. Urine drawn by catheter contained blood.

February 12th. Slightly better ; temperature, $98.8^{\circ}$; urine, 17 ounces in Fehruary 12 th. Slightly better; temperature, $98.8^{\circ}$; urine, 17 ounces in
twenty-four hours, which contained a large quantity of recent blood there was some tenderness in the left loin. He was kept lying flat in bed with lan ice bag to the left loin. His temperature was between $99^{\circ}$ and $100^{\circ}$ for a week; hæmaturia at first copious, continued daily until February 19 th, when it ceased.

On February 21 st some blood staining, the result of sugillation, was obvious in the left lumbar region. About this time bimanual palpation in the left ilio-costal space discovered a reniform tumour about twice the size of an ordinary kidney, tender to pressure ; the abdomen was lax, and the patient thin, and this lumbar tumour was easily defined by several who examined the patient. During the next fortnight he steadily improved, the urine was normal, and the tumour in the loin became less palpable. He was discharged on March 13th,' and has since presenter

Cases I and Ir are presumably examples of hydronephrosis from blockage of the ureter arising from injury. In Case $I$ there was no peritonitis, or cellulitis, or fever from first to last; there was no evidence of urinary extravasation, and therefore no evidence of rupture of ureter or pelvis of kidney. The hæmaturia was slight, early, and transient; the time and origin of the hydronephrosis do not suggest blood blockage of the ureter as the cause. The examinations of his abdomen between November 5 th and November 30 th, and the fact that his daily urine equalled more than 20 ounces, confirm my belief that up to the time of his first discharge from hospital the right ureter was still pervious to urine. The most plausible explanation to my mind of the subsequent hydronephrosis is either that the ureter bruised at the time of the run-over subsequently underwent a cicatricial contraction and occlusion, or that, involved in the pelvic fracture, it sustained compression by blood or callus from without, and consequent obliteration. That the occlusion of the ureter was absolute I infer from the rapid reaccumulation of the fluid after the early aspirations. Thus I usually found the swelling completely reformed in twenty-four hours during December, 1889 , that is to say, from $\frac{1}{2}$ to 1 pint of dilute urine was excreted before the pressure which it then began to exercise on the renal epithelium rapidly reduced secretion to zero. That the subsequent progressive diminution of the hydronephrotic fluid resulted from renal atrophy, from pressure and not from reopening of the ureter as the progressive increase in urine passed per urethram might suggest, I argue from the obvious thinning to husk-like tenuity of the sac, of which repeated examination assured me, and from the small and progressively lessening amount of urea the aspirated fluid contained.

Cases of partial or complete rupture of a ureter, or of rupture of the renal pelvis with consequent extravasation, and encysted urine, and subsequent perinephritis, occasioning lumbar urinary cysts have been not infrequently nor unnaturally confounded with traumatic hydronephrosis from ureteral blockage.

Of this class of injury no better recorded case than that of Barker ${ }^{3}$ could be desired, in which nephrectomy following unsuccessful drainage cured a case of encysted urinary extravasation in the loin due to ruptured ureter. Barker, in his clinical lecture on this case, alluded to the cases recorded by Stanley $^{4}$ in 1832 and 1844 as the only similar ones published up to that time either at home or abroad. In one of Stanley's cases a woman knocked down by a cart had high fever and a swelling in the right loin, from which several pints of urinous fluid were drawn, and who died ten weeks after. A postmortem examination was made. A large cyst behind the peritoneum bounded by lymph and thickened cellular tissue contained fœtid urine and pus communicating by a passage with a large hole in the pelvis of the right kidney. The treatment of that time besides puncture consisted of "bleeding from the arm, application of leeches to the abdomen, and calomel with antimony freely administered.'

I may mention an observation which $I$ made in my case which, along with the absence of fever, seems to prove that no perinephritis was present, namely, that it was very noticeable that the cystic tumour occupied a relatively lower and lower position as time went on. It seemed that the hydronephrosis

3 Lancet, January 17th, 1885, p. 95 .

4 Medico-Chir. Trans., vols. xviil and xxvi. 
dragged upon the perirenal fat, the mesonephron, and the vessels when the boy walked about, and consequently sank towards the pelvis, an event improbable if perinephritis had occurred.

A case closely resembling my Case I is recorded by Croft. ${ }^{5}$ A boy, aged 12, fell at leap-frog and hurt his left loin; some hæmaturia occurred for six days; he was discharged on the fourteenth day free from pain or tumour, but readmitted on the forty-ninth day with a large hydronephrosis. Urine passed was 14,18 , and 20 ounces on three successive days; no fever ; aspiration gave 79 ounces clear fluid of 1008 specific gravity and much relief. Eight aspirations sufficed to cure him.

Croft speaks of Stanley's cases as similar to this, but there is no reason to think that the sac in Croft's case was other than the kidney cavity itself. Pye-Smith ${ }^{6}$ attributes a case of hydronephrosis to stricture of the ureter resulting from a kick in the loin two years previously, when hæmaturia had occurred. Roberts ${ }^{7}$ speaks of inflammation of the ureter as a cause of obstructive hydronephrosis. Soller, ${ }^{3}$ of Lyons, has recorded a case in which he suggests that a blow under the floating ribs started a cellulitis of the iliac fossa, and so caused consequent obstruction of the ureter and hydronephrosis; the case was verified by a post-mortem examination. Hicks ${ }^{9}$ gives the case of a boy, aged 11, kicked in the right loin by a horse ; collapse, local pain, no fever; copious hæmaturia ensued; three weeks later hydronephrosis ; aspirated to two pints of fairly alkaline fluid, specific gravity 1010 , with a large amount of $\mathrm{NaCl}$ and trace of albumen; after two more aspirations there was no reaccumulation to be felt in the loin. Cabot ${ }^{10}$ relates a case in a boy, aged 10, who developed a right hydronephrosis several weeks after a fall downstairs, which was followed by two or three days' hæmaturia; aspiration yielded 44 ounces of clear, slightly yellow fluid, of specific gravity 1007, alkaline, $\frac{1}{4}$ per cent. of albumen; nine days later the fluid had reaccumulated; he decided to drain by lumbar incision, stitching the cyst to the wall of the abdomen ; in spite of antiseptics and carboluria, there was some fever and some pus, but later the wound closed, and he thinks the "ureter must have again become pervious."

Twice within recent years there have been short discussions on traumatic hydronephrosis at the societies. On April 5th, at the Medical Society, Dr. Lowe ${ }^{11}$ read a paper on the subject, occasioned by the case of a man, aged 20 , who, ten weeks after a "run-over," developed hydronephrosis. Nine pints of clear but highly albuminous fluid were drawn off; the cyst was again tapped and injected with iodine. There had been no hæmaturia, though he regarded obstruction of the ureter by blood clot as the probable cause. Mr. Pitts narrated a similar case in a girl, aged 9 , who, six weeks after being run over, had a left hydronephrosis of 41 ounces; after three tappings, massage was said to have effected a cure. Mr. Pitts had seen blood casts of the ureter passed. On November 28th, 1890 , at the Clinical Society, Dr. Goodhart ${ }^{12}$ narrated two cases of hydronephrosis cured by natural effort. The first was that of a young man, who fell, struck his right side, had sickness and hæmaturia, and pain for five weeks, when a swelling appeared in the injured loin; urine healthy, but only 14 to 26 ounces daily; 64 ounces of high-coloured, bloodstained urinous fluid, of specific gravity 1012, with trace of urea and 0.2 per cent. albumen, aspirated; after two more tappings it was left alone and completely disappeared. The second case was a boy of 8 , who fell, passed bloody urine, and developed later "an enormous cyst," which in the course of a year disappeared without treatment. Dr. Hadden cited a similar case, a woman of 22 , who, shortly after a kick in the abdomen, developed a hydronephrosis; the urine was normal in quality; after six weeks in bed and a consultation-at which it was decided not to operate-she got up, and next day the tumour disappeared, with a coincident increase in urine passed. Lastly, Dr. Knox ${ }^{13}$ reported a case in December 1891 , in which he drained the cyst. A man of 42 , for three

5 Clinical Soc. Trans., vol, xiv, 1880-1, p. 107

6 Path. Trans., vol. xxiii, p. 159

7 Urinary and Renai Diseases, 1885.

8 Lyon Médical, xxxv, 1880, p. 333.

9 New York Medical Record, April 17th, 1880, p. 424

10 Boston Medical and Surgical Journal, vol. cviii, No. 8, p. 123.

11 Lancet, April 10th, 1886, p. 689.

12 lbid., December 6th, 1890 p. 1819

13 Ibid., December 19th, 189i, p. 1384. days after a squeeze of the abdomen between a waggon and a chain had hæmaturia and colic; three weeks later a tumour formed in the left loin; the urine was normal in quantity and quality. Three months after the accident Dr. Knox opened and drained the cyst from the front, evacuating some 12 pints of dark-red limpid fluid. At first the discharge was copious and urinous ; two months later there was none and the sinus healed. The history of this case-especially the normal quantity of the urine, the amount of the fluid and its site, and the rapid closure of the sinus-make me look upon this case as probably one of a small rupture of the ureter or pelvis of the kidney without imperviousness of the ureter or distension of the kidney - a case of pseudo-hydronephrosis, like those of Stanley and Barker, and akin to a case recently reported by Mr. W. H. Allingham. ${ }^{14}$ To such cases the term "traumatio hydronephrosis" would be incorrectly applied; they are not cases of hydrorenal distension, but of encysted extravasations of urine from ruptured ureter. Poland, in $1869,{ }^{15}$ gives the result of a post-mortem examination in a case of rupture of the ureter. A multipara of 33, in the fifth month of pregnancy, fell from a railway carriage, bruising the right ilium and loin and lacerating the abdominal parietes ; vomiting and almost complete urinary suppression followed, and on the fourth day abortion took place; there were febrile symptoms from the third day till death on the sixth day. Post mortem the "right ureter was torn quite across just below the pelvis of the kidney;" the parts around were in "a gelatiniform condition and smelt putrescent;" no peritonitis.

My third case can only admit of speculative explanation, but I am inclined to regard it as a case in which intracapsular laceration of the kidney gave rise at first to copious hæmaturia, and, later, to blood blockage of the ureter, which, however, passed off, the kidney being temporarily the subject of "acute hydronephrosis."

The cases I record, and the brief review of other cases which I have given, will, I think, permit of the following generalisations :-

1. "Traumatic hydronephrosis," or hydrorenal distension, the result of the proximate or remote effects of traumatism upon the perviousness of the ureter, must be distinguished from cases of encysted extravasated urine causing loin tumours, the result of partial or complete rupture of the ureter.

2. Traumatic hydronephrosis may arise acutely from blood blockage of the ureter or, more slowly, from bruising of the ureter, resulting in ulceration and stricture, similar to the more familar process in the urethra. Possibly also from results of pelvic fracture or bruising by virtue of extrinsic pressure by blood clot, inflammatory products, or callus.

3. Traumatic hydronephrosis may result in spontaneous cure, least probably when confirmed and chronic; or, if in the latter cases spontaneous cure result, it will be in the sense of destruction of the secreting renal epithelium and obsolescence of the kidney. Massage may facilitate the restoration of the perviousness of the ureter.

4. Aspiration is valuable to relieve dangerously rapid kidney distension following injury. In my first case, too, I consider it facilitated the shrinkage of the kidney sac, while permitting sufficient tension on the renal epithelium in the intervals to effect its destruction, at the same time permitting the gradual assumption of double duty by the opposite kidney.

5. When there is reason to believe that the condition is one of pyo-hydronephrosis, and where nephrectomy is inadmissible, and when the patient's general health is suffering, nephrotomy, stitching the sac to the parietes, and drainage are indicated. When the ureteral block is permanent the persistence of a urinary fistula, however, is probable, because we have then lost the beneficial destructive influence of tension. In $\mathrm{my}$ second case, the adhesions and relations of the sac in a man not over-strong, and whose other kidney was not eliminating the normal amount of urea, induced me to prefer drainage to either nephrectomy or aspiration.

6. In the cases of pseudo-hydronephrosis from ruptured ureter, incision and drainage must almost certainly be called for sooner or later by inflammatory consequences. If at the operation it is evident that the rupture of the ureter is such

14 Ibid., December 6th, 1890, Medical Society's meeting, p. 1224. 15 Guy's Hospital Reports, vol. Xiv, p. 85. 
as to render the likelihood of restoration of its function improbable the removal of the kidney, as in Barker's case, would seem to be strongly indicated. Such cases should offer the best results for nephrectomy, and would hardly be liable to the heavy rate of mortality referred to that operation when the nature of the cases for which it is performed is undistinguished. Each case, however, should be judged upon its own merits before nephrectomy is advised. It is, however, obvious that the logical choice is rather between aspiration and nephrectomy than between nephrectomy and either of the other procedures.

\section{ON THE RARER FORMS OF FRACTURE OF THE CARPAL EXTREMITY OF THE RADIUS. ${ }^{1}$}

By E. H. BENNETT, M.D., F.R.C.S.I., Professor of Surgery in the University of Dublin.

THE list of fractures of the lower end of the radius runs thus : 1. Colles's fracture (three varieties)

2. Colles's fracture reversed.

3. Epiphysary separation.

4. Rhea Barton's fracture.

5. Rhea Barton's fracture reversed.

6. Fracture of the radial styloid.

7. Longitudinal fracture or fissure of the lower end of the bone.

I propose to submit very briefly some examples which illustrate the pathology of the second and last of these groups. I have already published ${ }^{2} \mathrm{my}$ views with regard to Colles's fracture, and I think $\epsilon$ stablished the features of its three varieties by the detailed examination of an ample pathological series, which numbers over a hundred examples. I shall refer to these varieties only so far as is unavoidable in the discussion of the reversed Colles's and the longitudinal fractures contained in No. 7. Epiphysary separations have had their features so fully and clearly delineated by Professor R. W. Smith that I need not speak of them.

4 and 5-Rhea Barton's fracture and its reverse-are now admitted to be only Colles's fracture, and the groups are of interest only as they serve to record the fact that this observer as long ago as 1838 recognised the clinical features of the lesion which modern American writers attribute to Smith as its describer, that is, reversed Colles's.

The view Rhea Barton held of these injuries was that in the first and most common injury extreme extension of the wrist pressed the carpal bones so heavily against the dorsal margin of the carpal articular surface of the radius that this margin broke off.

In the rarer injury overflexion of the wrist pressed, according to the author, the carpus so hardly against the anterior border of the radial carpal surface as to carry it away.

One of the latest American writers ${ }^{3}$ on the subject disposes of this fracture thus: "In the forty-five years which have elapsed since the publication of these views there has not been, so far as I have been able to ascertain, a single instance placed on record in which they have been confirmed by dissection." I can fully endorse this statement, and should not have placed the groups in my list but for the fact that the textbooks of our American fellow-workers in general include them, and for the fact that, though in error in his pathological detail, it is clear that Barton was amongst the first observers of his time; that he recognised Colles's fracture and its reverse as distinguished from dislocation of the wrist. I may therefore pass this section of the subject by stating only that I can produce many specimens which might, at the first glance, be put down as Barton's fracture, but they are all reducible to fractures of the carpal surface secondary to the occurrence of impaction in Colles's fracture.

I now submit a few facts as to the reversed Colles's fracture, which would probably have remained for some time unpublished but that the chance of daily surgical practice has enabled me to record a case observed in the living, a tangible record of which I have preserved in this cast.

Here is Smith's cast of the injury, which is his only fact,

1 Read at the Royal College of Surgeons in Ireland before the Pathological Section of the Royal Academy of Medicine in Ireland.

2 BRITISH MEdical JoURNÁl. May 22nd, 1880.

3 Packard Asluurst's Encyclopædia, vol. iv, p. 168. and it is clear to anyone who reads the description that the history of the case was not in his possession, for he gives us no details regarding it. He says : "I cannot speak with accuracy as to the anatomical characters of the injury, having never had the opportunity of examining after death the skeleton of the forearm in those who had during life met with this accident, nor is there any preparation showing the exact relative position of the fragments in any of the pathological collections in Dublin."

Hamilton, in his sixth edition, 1880, refers to the rarity of this fracture, and quotes part of the passage $I$ have just read in support of this view. Mr. Callender's two specimens of this injury and a single clinical observation seem to be the total of London cases.

Professor Gordon ${ }^{5}$ published a woodcut representing the radius broken in this manner, and states that there exists a second pathological specimen of the fracture in the Museum of the Queen's College, Belfast; but he says: "I have not met with the accident in the living." Yet on this slender stock of facts he names the injury the "articular fracture of the lower end of the radius "-a name most inappropriate, as it would lead a novice to suppose that this alone of fractures of the lower end of the radius involved the radio-carpal joint.

Of the eight specimens of this fracture before the Academy, three present their carpal surfaces unbroken, and five have these surfaces more or less fissured by fractures. I think that these comminutions have resulted from the same cause as that which produces the comminutions of the lower fragment in ordinary Colles's fracture, namely, the intrusion of the lower end of the upper fragment into the lower, which causes a greater or lesser degree of splintering of the lower. The fact that three of these specimens and the example figured by Voillemier ${ }^{6}$ are fractures which do not involve the wrist-joint disposes of Professor Gordon's name for the injury - "the articular fracture." In all these examples the radius is broken transversely as in Colles's fracture; but the lower fragment, in one piece or comminuted, is displaced forwards.

The injury recorded by this cast was the following:-A jockey, aged 19, was backing for the first time a three year old filly, she bucked and burst the girths, and sent saddle and rider into the air. The rider fell to the ground, striking first on the back of his right hand. I saw him the day following. The injury had been readily recognised by the deformity, the facility of reduction and the distinct osseous crepitus felt on the reduction; immediately on the relaxation of the reducing force the deformity recurred. I took the patient into hospital and verified the details, and treated the patient until union was obtained.

It would seem then that Rhea Barton and Mr. Callender were hitherto the only observers of the clinical details of the injury, and that the pathological facts bearing on it were not much more plentiful here or in America. I need not then apologise when I submit a cast of the recent injury taken previous to reduction, and a series of eight pathological specimens obtained, one from the museum of this college, to which it was presented by Mr. Swan, in 1885, and the seven which I have myself procured from the anatomical department of the School of Physic in Ireland. I think we may then fairly reject the conclusion arrived at by $M$. Lecomte, who states his opinions in a series of dogmatic assertions, of which this is the first: "All the fractures of the inferior extremity of the radius are produced by a single and the same class of fall ; falls on the palm of the hand."

It is I think clear that the reversed Colles's is the result of a fall on the back of the hand. I shall now briefly examine the longitudinal fractures of the lower end of the radius, and I hope show that they risult from causes other than falls on the palm of the hand. The leading case which bears on this question is that recorded by Bigelow. The Catalogue of the Warren Museum contains this description of the specimen, 1035. "The lower extremity of the radius showing a stellate crack of the articular surface and extending upwards for more than an inch. From a patient, who died of other injuries. At first there was only a complaint of lameness as from a sprain, but after some days there were swelling and tender-

4 On Fractures in the Vicinity of Joints, R. W. Smith, 1847, p. 163. 5 Fractures of the Lower End of the Radius, 1875, p. 30. 6 Clinique Chirurgicale, Pl. 1, Fig. 1. 